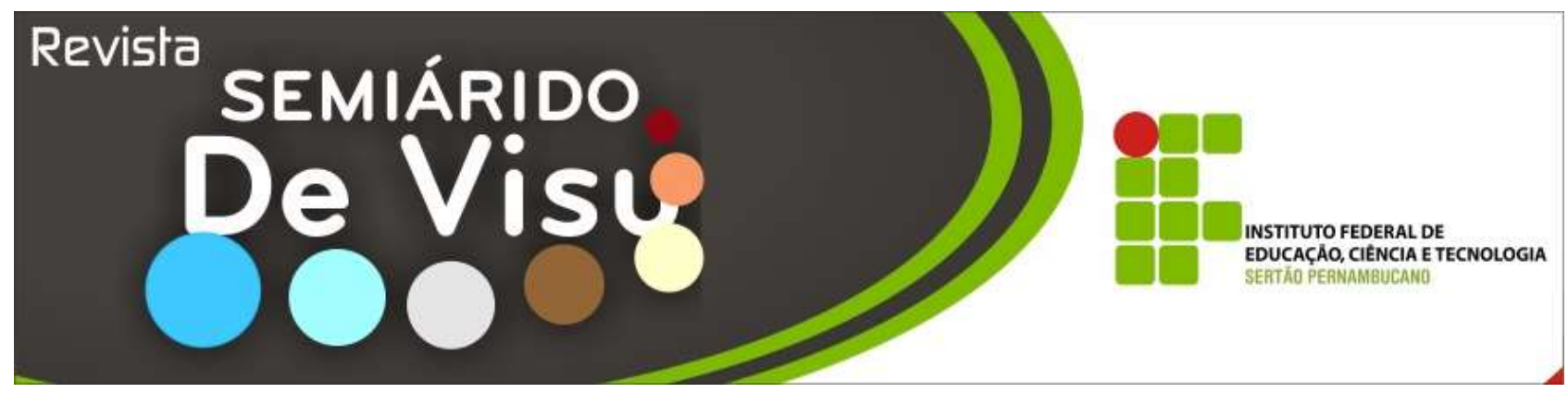

\title{
Análise geomorfológica do município de Lucena-Paraíba utilizando imagens SRTM
}

\author{
Erika Rodrigues Dias ${ }^{1}$, Marconi Antão dos Santos² \\ 1,2, Instituto Federal de Educação, Ciência e Tecnologia da Paraíba - Campus de João Pessoa/PB. Avenida Primeiro de Maio, nº 720. \\ Jaguaribe, João Pessoa - PB, CEP: 58.015-435. Telefone: (83) 3612-1200 / E-mail: \\ erikageo.rodrigues@gmail.com; ${ }^{2}$ marconi@ifpb.edu.br.
}

RESUMO: Uma das grandes preocupações da atualidade encontra-se no uso racional das terras, conciliando aspectos sociais, econômicos e ambientais. Sendo assim, esse trabalho teve por objetivo realizar a análise geomorfológica, utilizando as geotecnologias, através da metodologia taxonômica proposta por Ross. Os materiais utilizados nesse trabalho foram imagens de radar da missão Shuttle Radar Topography Mission - SRTM, imagens obtidas do Google Earth e softwares específicos. Como resultado foi obtido o mapa hipsométrico e clinográfico da área em estudo, a representação tridimensional do relevo e a caracterização geomorfológica da superfície do município que permitiu classificar como $1^{\circ}$ táxon a Formação Barreiras; o $2^{\circ}$ táxon como sendo as unidades geoambientais da Planície litorânea e dos Baixos Planaltos Costeiros; o $3^{\circ}$ táxon como formas com topos tabulares, formas de escarpas, formas de planície interdial e formas de campos de dunas; o $4^{\circ}$ táxon apresentando dissecações do tipo $21,22,23,25,31$ e 32 ; e o $5^{\circ}$ táxon com vertentes mistas, possibilitando a geração do mapa geomorfológico do município de Lucena.

Palavras-chave: relevo, geotecnologias, geoprocessamento.

\section{Geomorphological analysis of the city of Lucena-Paraíba images using SRTM}

\begin{abstract}
One of the great concerns nowadays is related to the rational use of the lands, uniting social, economic and environmental aspects. In this way, this research aimed to use the geotechnologies to make the geomorphological characterization using the taxonomic methodology proposed by Ross. For doing so, mission radar images from Shuttle Radar Topography Mission-SRTM, images obtained from Google Earth and specific software. As a final product there was the hypsometric and clinographic map of the studied area, the tridimensional representation of the relief and the geomorphological characterization of the city surface, which allowed to classify as 1 taxon Barriers to Training; 2nd taxon as the geo-environmental units of the coastal plain and the Coastal Tablelands Netherlands; 3rd taxon as tabular forms with tops of cliffs forms, shapes and forms of interdial plain fields of sand dunes; 4 showing the dissection of the type taxon $21,22,23,25,31$ and 32 ; and the 5th taxon with mixed strands, enabling generation of the geomorphological map of the city of Lucena.
\end{abstract}

keywords: relief, geotechnology, geoprocessing. 
(DIAS; SANTOS, 2016)

\section{Introdução}

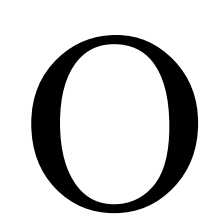

S conhecimentos científicos advindos da geomorfologia têm contribuído de forma expressiva para uma melhor compreensão das interrelações entre os processos naturais e sociais que atuam sobre o relevo e que auxiliam na gestão territorial, mas para que se possa gerir um território é necessário conhecêlo. Para tanto existem as geotecnologias destinadas a indicar a posição geográfica dos objetos, contendo diversas ferramentas de análise, monitoramento e identificação de áreas através de produtos como imagens orbitais, fotografias aéreas, que permitem desenvolver pesquisas referentes ao uso e ocupação das terras, aos impactos da ação antrópica sobre os recursos naturais e análise de feições geomorfológicas e elaboração de documentos cartográficos.

Os documentos cartográficos são considerados importantes insumos na área da geomorfologia por expressar uma realidade relativamente abstrata do relevo, que, aliada as tecnologias do geoprocessamento e aos sistemas de informação geográfica (SIG), possibilitam a representação do espaço.

Contudo, para realizar estudos geomorfológicos, além de ferramentas adequadas para tratamento das informações é necessário dispor de dados altimétricos referentes à área de interesse.

Para o presente estudo foram utilizados os dados contidos nas imagens de radar da missão SRTM (Shuttle Radar Topography Mission) disponibilizados no Brasil pela EMBRAPA (Empresa Brasileira de Pesquisa Agropecuária), que, de acordo com USGS (2014), foi uma missão da NASA (National Aeronautics and Space Administration) realizada no ano de 2000 objetivando realizar um levantamento altimétrico da superfície da Terra a partir de um sistema de radares.

As superfícies mais planas são mais difíceis de representar no ambiente do computador devido às limitações das imagens de radar em representar esta taxonomia. Contudo, esse tipo de dado permite representar o desenvolvimento das formas de relevo mais heterogêneas através da extração de informações como curvas de níveis e da geração de mapas temáticos hipsométrico e clinográfico.

Através da geração do mapa hip sométrico é possível realizar operações de medição das altitudes dos diversos pontos do relevo e representar num plano as diferenças altimétricas existentes no relevo.

O mapa clinográfico é de grande importância por representar a distribuição espacial dos graus de inclinação de uma superfície permitindo estudos diversos referentes a paisagem do terreno, corresp ondendo à diferença altimétrica existente entre dois pontos do terreno. O mapa do modelo digital do terreno (MDT) é fundamental para compreensão da variação altimétrica da superfície, pois permite gerar representações tridimensionais da área em estudo.

Um modelo digital do terreno, segundo Camara \& Medeiros (2004), é uma representação matemática computacional da distribuição de um fenômeno espacial que ocorre dentro de uma região da superfície terrestre. Este modelo pode ser gerado a partir de curvas de nível e pontos altimétricos.

A partir do modelo digital do terreno, de acordo com Freire (2007), é possível delimitar áreas de bacias hidrográficas, gerar perfis de terreno a partir do mapa de declividade, calcular dimensão e perímetro da região de estudo, visualizar áreas de vertentes auxiliando em projetos de drenagem e áreas de assentamentos humanos.

As contribuições dos mapas hip sométrico, clinográfico e outras representações como as tridimensionais, que representam a estrutura do relevo, devem-se ao fato destes proporcionarem inúmeros subsídios para desenvolvimento de diagnósticos e outros estudos visando o planejamento urbano.

No Brasil, em muito se divergem as classificações geomorfológicas por não existir uma padronização entre os estudiosos. Ab'Sáber foi o geomorfólogo que começou os estudos sobre relevo no Brasil, cuja classificação abrangia três táxons: o primeiro táxon compreendendo as morfoestruturas que são os maiores táxons da compartimentação do relevo; o segundo táxon compreendendo as morfoesculturas que são as formas com características genéticas comuns agrupando 
feições semelhantes; e o terceiro táxon compreendendo a fisionomia da paisagem que são definidas pelo arranjo de formas altimétricas. Jurandir Ross aperfeiçoou a compartimentação de Ab'Sáber dividindo o relevo em seis táxons, mantendo os três primeiros táxons e acrescentando mais três, o $4^{\circ}$ táxon, o $5^{\circ}$ táxon e o $6^{\circ}$ táxon. O quarto táxon compreende os tipos de formas de relevo; o quinto táxon compreende os tipos de vertentes (côncavo, convexo); e o sexto táxon compreende as formas de processos atuais (voçorocas, deslizamentos).

Neste trabalho foi utilizada a proposta taxonômica de Ross (1992), por ser mais precisa abrangendo táxons de menor escala não contemp lados pela proposta de Ab'Sáber, para realizar uma caracterização geomorfológica do município de Lucena por essa área possuir poucos estudos relacionados ao relevo que permitam quantificar fatores como vulnerabilidade e servir de base ao planejamento territorial e ao uso e ocupação do solo do município. Além disso, Lucena, segundo o censo 2010 do IBGE, possuía, nesse ano, uma população de 11730,00 habitantes com população estimada para 2013 de 12460 habitantes, distribuídos em um município com $89 \mathrm{~km}^{2}$ de área, ou seja, é uma região que ainda tem potencial para se desenvolver de forma planejada. Por isso, é de grande importância estudos sobre o relevo dessa região, utilizando sistemas de informações geográficas, para servir de auxílio ao planejamento do território

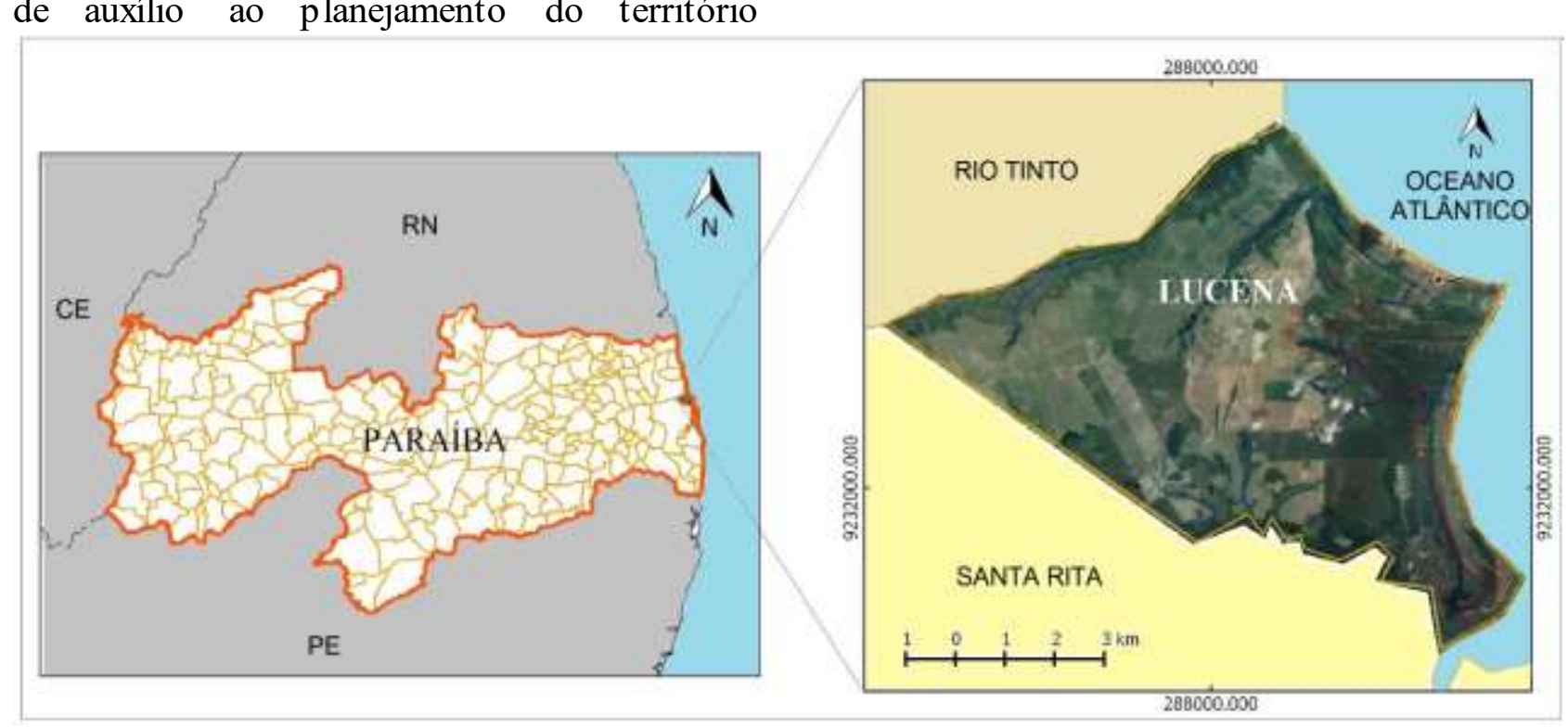

Figura 1. Mapa de localização do município de Lucena. municipal e para a determinação de áreas próprias e impróprias ao uso e ocup ação urbana do solo.

Sendo assim, o objetivo desse trabalho foi realizar uma análise geomorfológica, a partir de imagens de radar do SRTM, gerando documentos cartográficos referentes ao relevo, como os mapas hipsométrico e clinográfico assim como o modelo tridimensional do terreno, com a finalidade de servir como subsídio à gestão territorial. A escolha em utilizar imagens SRTM nesse trabalho deriva da enorme possibilidade em estudos geomorfológicos que essas imagens permitem realizar, como afirma Grohmann et al. (2008), que entre outras características, o SRTM permite o cálculo de variáveis topográficas com rapidez, a identificação de formas de relevo e de estruturas que seriam mascaradas pela vegetação em imagens ópticas.

\section{Metodologia}

\section{Área de estudo}

Inicialmente foi realizada uma pesquisa documental sobre a área em estudo, que corresponde ao município de Lucena, que de acordo com CPRM (2005), está localizado na Microrregião Lucena e na Mesorregião da Mata Paraibana do Estado da Paraíba. A Figura 1 configura a localização do município de Lucena. 
(DIAS; SANTOS, 2016)

Este município, segundo CPRM (2005), está inserido na unidade geoambiental dos baixos planaltos costeiros, unidade que acompanha o litoral de todo o Nordeste, apresentando altitude média de 50 a 100 metros e que compreende platôs de origem sedimentar, que apresentam grau de entalhamento variável, ora com vales estreitos e encostas abruptas, ora abertos com encostas suaves e fundos com amp las várzeas.

Lucena é contemplada pela presença de outra unidade geoambiental bem definida, a planície litorânea, que em períodos chuvosos recebe grande carga de sedimentos e de escoamento superficial, por isso é fundamental conhecer a topografia dessa superfície buscando identificar as regiões mais vulneráveis à ocorrência de desastres ambientais como inundações e deslizamentos de terra. Essa região possui um clima do tip o Tropical Chuvoso, com verão seco onde o período chuvoso começa no outono tendo início em fevereiro e término em outubro onde a precipitação média anual é de $1634,2 \mathrm{~mm}$, encontrando-se inserido nos domínios da bacia hidrográfica do Rio Miriri. Todos os cursos de água do município têm regime de fluxo perene e o padrão da drenagem é do tipo dendrítico, que recebe esse nome devido a sua semelhança com galhos de uma árvore (CPRM, 2005). Foi calculada a área do município compreendida na unidade dos baixos planaltos costeiros, ou tabuleiros costeiros, no SPRING, e foi constatado que, essa unidade geoambiental, na qual predominam atividades destinadas à agricultura, pastos correspondendo a zona rural do município de Lucena, representa cerca de $74 \mathrm{~km}^{2}$ da área total do município, ou seja, mais de dois terços do município, enquanto que a unidade da planície litorânea compreende o perímetro urbano do municíp io que representa $15 \mathrm{~km}^{2}$ do total, ou seja, cerca de um terço do município, como mostra a Figura 2.

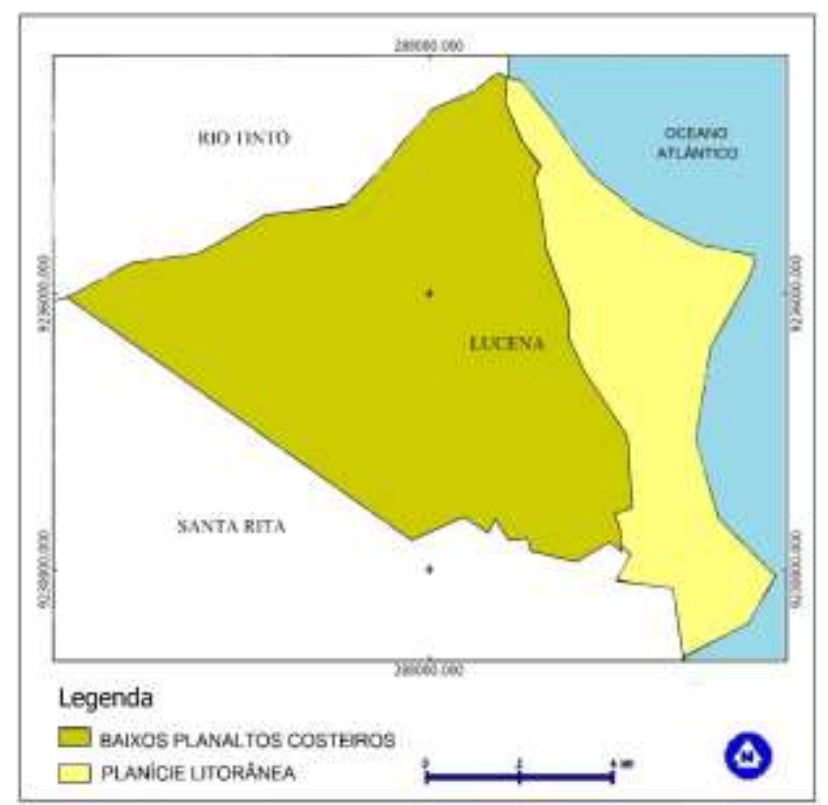

Figura 2. Mapa das unidades geoambientais de Lucena. Fonte: Erika Rodrigues Dias (2014) adaptado de CPRM (2005).

\section{Materiais e Métodos}

Os materiais utilizados para atingir os objetivos propostos constituíram-se de imagens obtidas do Google Earth, que foram utilizadas para verificar a real ocupação e distribuição da ocupação urbana no município de Lucena, e imagens da missão Shuttle Radar Topography Mission (SRTM) que são imagens de radar que possuem informações altimétricas com resolução espacial de 90 metros, que são os dados originais para a região em estudo, apesar de já existirem dados refinados deste mesmo radar para 30 metros de resolução espacial. Isso 
porque, as interpolações, com qualquer dos métodos disponíveis, não alteram significativamente os dados originais (Penha e Silva, 2012). Dessa forma, optou-se por utilizar os dados originais para a realização do presente estudo.

As imagens de radar do SRTM (Shuttle Radar Topography Mission) foram obtidas no site da Embrapa, no qual foi escolhido o quadrante que corresponde à área de interesse, que neste caso se refere à carta SB-25-Y-A.

$O$ procedimento consistiu na importação das imagens de radar e recorte da imagem SRTM, no SPRING versão 5.1.7, utilizando como máscara de corte o limite do município de Lucena obtido no site do Instituto Brasileiro de Geografia e Estatística (IBGE). O sistema de coordenadas utilizado nesse trabalho foi $\mathrm{O}$ Universal Transversa de Mercator (UTM) e o Datum foi o SIRGAS2000 (Sistema de
Referência Geocêntrico para as Américas), zona 25, Hemisfério Sul.

Para a obtenção do mapa hipsométrico inicialmente foram extraídas as curvas de nível, equiidistantes 10 metros, a partir da qual foi gerada uma grade retangular. Posteriormente, foi realizado o fatiamento das faixas de altitude, a cada 10 metros para as menores altitudes, devido à presença da unidade geoambiental da planície litorânea, que apresenta pouca variação altimétrica, e a cada 20 metros para as maiores altitudes. Em seguida foi gerada a carta hipsométrica da região e obtidos dados quantitativos referentes a área, em $\mathrm{km}^{2}$, abrangida por cada classe altimétrica, como mostra a $\quad$ Tabela 2. Esses procedimentos foram realizados no SPRING utilizando a ferramenta Temático e Medida de classes.

Tabela 2. Área do município de Lucena ocupada por cada classe altimétrica determinada.

\begin{tabular}{ll}
\hline Classes Altimétricas & Área $\left(\mathbf{k m}^{\mathbf{2}}\right)$ \\
\hline $0-10$ & 31,65 \\
$10-20$ & 7,07 \\
$20-40$ & 13,84 \\
$40-60$ & 19,25 \\
$60-80$ & 14,08 \\
$80-100$ & 3,60 \\
$>100$ & 0,12 \\
\hline
\end{tabular}

Posteriormente foi elaborado o mapa clinográfico. Para tanto foi criada uma categoria denominada declividade, no SPRING, e, em seguida, informados os planos de informação (PIs), amostra, grades, TIN e imagem. Na barra de ferramentas MNT foi selecionado o ícone declividade e posteriormente foi escolhida a entrada (Grade), a saída (Declividade) e unidade porcentagem transformando as curvas de nível em porcentagens de inclinação. A Figura 3 mostra a determinação dos intervalos das classes de declividade que foi baseada nos critérios de vulnerabilidade proposto por Ross (1994).

Tabela 3. Declividade da área municipal

\begin{tabular}{lll}
\hline Vulnerabilidade & Declividade (\%) & Área $\left(\mathbf{k m}^{\mathbf{2}}\right)$ \\
\hline 1. Muito Baixa & $0-6$ & 67,57 \\
2. Baixa & $6-12$ & 14,28 \\
3. Média & $12-20$ & 3,88 \\
4. Alta & $20-30$ & 0,12 \\
\hline Fonte: Ross (1994). & &
\end{tabular}


(DIAS; SANTOS, 2016)

A partir da imagem SRTM, foi possível extrair, automaticamente, a rede de drenagem no software ArcGis, utilizando a ferramenta Spatial Analyst Tools - Hidrology. Foi gerado um modelo tridimensional do terreno, no SPRING, através de uma composição colorida RGB dos planos de informação de declividade, de hipsometria e de sombreamento de relevo, respectivamente, utilizando a ferramenta de visualização em 3D. A esse modelo tridimensional foi adicionada uma imagem de alta resolução obtida no Google Earth, com passagem em setembro de 2011, que foi georreferenciada no software Quantum GIS.
Por fim, a geração desses documentos cartográficos auxiliou na realização da caracterização e análise geomorfológica do território municipal, tendo por base a classificação taxonômica proposta por Ross (1992).

Nessa classificação, Ross compartimentou o relevo em 6 categorias que ele denominou de níveis taxonômicos. Os três primeiros táxons foram determinados de acordo com as características geológicas do relevo. $\mathrm{O}$ quarto táxon foi determinado utilizando como referência a matriz dos índices de dissecação do relevo proposto por Ross (1996), como mostra a Tabela 4.

Tabela 4. Matriz dos Índices de Dissecação das Formas de Relevo.

\begin{tabular}{cccccc}
\hline $\begin{array}{c}\text { Grau de Entalhamento } \\
\text { dos Vales }\end{array}$ & $\begin{array}{c}\text { Muito Grande } \\
(1)>1500 \mathrm{~m}\end{array}$ & $\begin{array}{c}\text { Grande (2) } \\
1500 \mathrm{a} 700 \mathrm{~m}\end{array}$ & $\begin{array}{c}\text { Média (3) } \\
700 \mathrm{a} 300 \mathrm{~m}\end{array}$ & $\begin{array}{c}\text { Pequena (4) } \\
300 \mathrm{a} 100 \mathrm{~m}\end{array}$ & $\begin{array}{c}\text { Muito } \\
\text { Pequena } \\
(5) 100 \mathrm{~m}\end{array}$ \\
\hline Muito fraco (1) $<20 \mathrm{~m}$ & 11 & 12 & 13 & 14 & 15 \\
Fraco (2) $20-40 \mathrm{~m}$ & 21 & 22 & 23 & 24 & 25 \\
Médio (3) $40-80 \mathrm{~m}$ & 31 & 32 & 33 & 34 & 35 \\
Forte (4) $80-160 \mathrm{~m}$ & 41 & 42 & 43 & 44 & 45 \\
Muito forte (5) $>160 \mathrm{~m}$ & 51 & 52 & 53 & 54 & 55 \\
\hline Fonte: Ross (1996). & & & & &
\end{tabular}

Para a classificação do $4^{\circ}$ táxon, foi realizado a medição do topo do relevo ao vale, no SPRING, para determinar o grau de entalhamento dos vales, assim como, a medição da distância entre os cursos d'água a partir do nível médio de um canal à outro, determinando assim, a dimensão interfluvial média. Todos os map as produzidos neste trabalho foram gerados na escala 1:100.000 devido à base de dados terem sido as imagens do SRTM.

\section{Resultados e Discussão}

A partir da imagem SRTM foi obtido o mapa contendo as curvas de nível e a grade de pontos, representado na Figura 3, extraídas dessa imagem de radar através do comando MNT e Geração de isolinhas, no software SPRING versão 5.1.7. 
(DIAS; SANTOS, 2016)

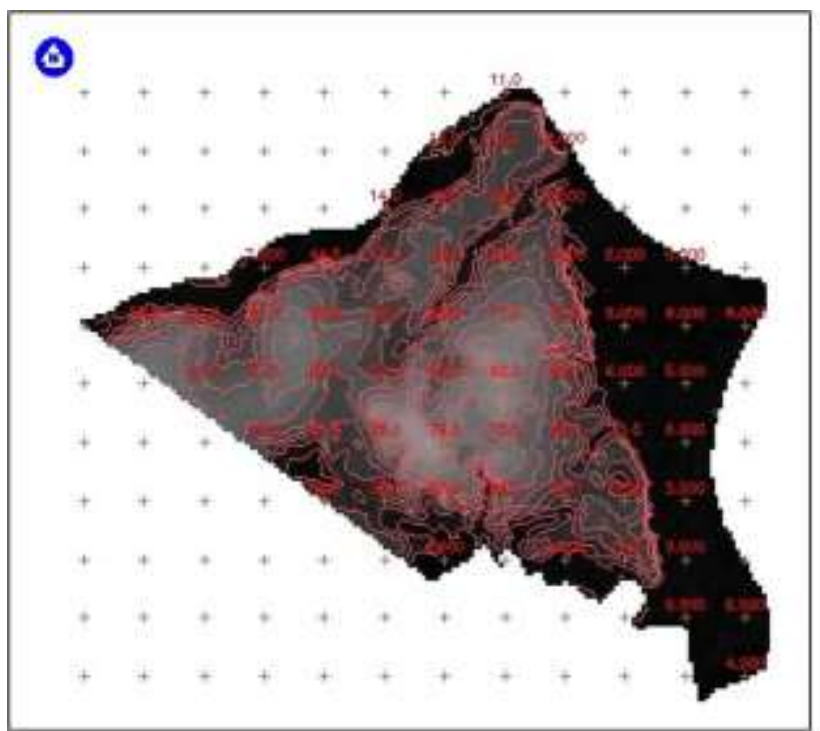

Figura 3. Curvas de nível e grade de pontos extraídas do SRTM.

Deste mapa contendo informações altimétricas foi gerado o mapa hipsométrico, representado na Figura 4, que possibilitou caracterizar a top ografia que compõe a área em estudo. Através da análise do mapa de hipsometria foi possível verificar que a altimetria do município oscila entre a elevação de 0 metros, e a elevação máxima do terreno, que corresponde a 105 metros. Na direção oeste, onde se localiza a área rural do município, predominam as altimetrias mais altas (> 40m) apresentando um relevo heterogêneo, enquanto que na direção leste, onde se localiza o perímetro urbano do município de Lucena, predominam as altimetrias mais baixas $(<10 \mathrm{~m})$ apresentando, dessa forma, um relevo bastante homogêneo.

$\mathrm{O}$ resultado da área compreendida em cada classe altimétrica classificada no mapa de hip sometria é mostrado na Tabela 2.

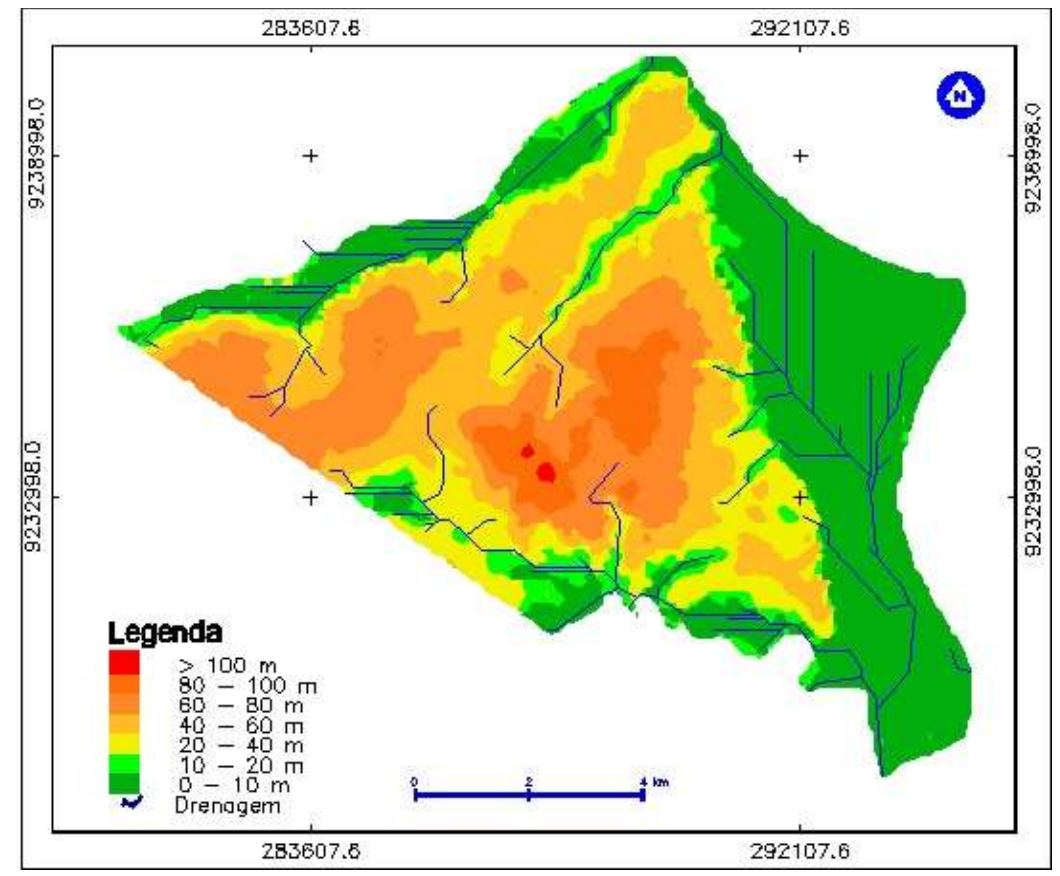

Figura 4. Mapa hipsométrico do município de Lucena.

Analisando a tabela 2 é possível perceber que apesar da predominância de terrenos com baixas altitudes, alcançando no máximo 10 metros, verifica-se a presença considerável de 
terrenos com altitudes mais significativas, como é o caso da classe que compreende elevações de 40 a 60 metros, que corresponde $19,25 \mathrm{~km}^{2}$ da área total de $89 \mathrm{~km}^{2}$, e da classe que compreende elevações de 60 a 80 metros, que corresponde a aproximadamente $14,08 \mathrm{~km}^{2}$ da área total do município.

Após esse procedimento foi gerado o mapa clinográfico, representado na Figura 5, que associado aos dados contidos na carta de hip sometria, possibilita determinar as áreas com alto potencial para a ocorrência de desastres ambientais. As classes de declividade foram hierarquizadas segundo as categorias de vulnerabilidade proposta por ROSS (1994), como mostra a Tabela 3, a partir da qual é possível perceber que a classe de declividade que predomina na área em estudo é a de vulnerabilidade muito baixa, representando $67,57 \mathrm{~km}^{2}$ da área total. Por sua vez, a classe que apresenta dados considerados de vulnerabilidade alta corresponde às menores extensões, correspondendo a $0,12 \mathrm{~km}^{2}$ da área total.

Entretanto é preciso considerar que existem áreas que apresentam relevos com inclinações consideráveis como é o caso da classe que compreende inclinações que variam de $6-12 \%$, representando uma área de 14,28 $\mathrm{km}^{2}$ da área total e que é considerada por Ross (1994) como de vulnerabilidade baixa, e da classe que compreende inclinações que variam de $12-20 \%$ que representa uma área de $3,88 \mathrm{~km}^{2}$ da área total e que é considerada por Ross (1994) como de vulnerabilidade média. Isso porque, apesar de não serem as declividades predominantes, estas áreas quando associadas às elevações do relevo, ao volume de precipitação local, à quantidade de vegetação presente na área, podem formar um quadro de áreas de risco em potencial.

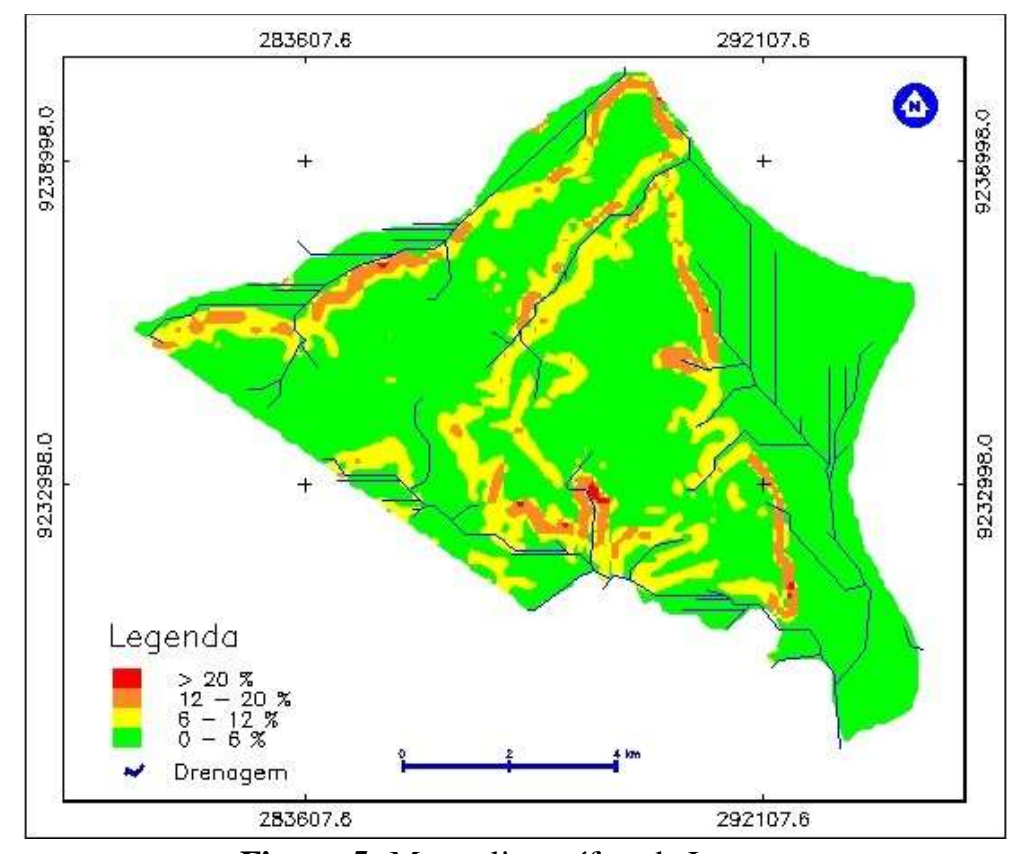

Figura 5. Mapa clinográfico de Lucena.

Analisando os produtos gerados, verificou-se que o perímetro urbano do município encontra-se inserido, em sua totalidade, na unidade geoambiental da planície litorânea, que apresenta uma superfície bastante homogênea, com pouca variação altimétrica apresentando um relevo com baixas inclinações.

Através dos mapas clinográfico e de hipsometria, foi possível verificar que no limite entre as duas unidades geoambientais, planície litorânea e baixos planaltos costeiros, predominam terrenos com altitudes de até 60 metros cujas vertentes apresentam declividades medianas de $6 \%$ a $12 \%$ que diminuem gradativamente na medida em que se aproxima do litoral, assim, com base nas informações apresentadas, é possível identificar que essas áreas são mais propensas a inundações por 
apresentar terrenos ondulados à planos recebendo, consequentemente, grandes quantidades de água oriundas do escoamento superficial proveniente dos terrenos mais elevados fato que pode representar riscos à população que se encontram localizadas próximas à essas áreas. Após a geração dos mapas temáticos acima descritos, foi gerado um modelo tridimensional do município de Lucena objetivando uma melhor visualização do relevo municipal. Para tanto foi realizada uma composição colorida RGB dos planos de informação declividade, hipsometria e relevo sombreado, respectivamente, no SPRING. Foi adicionado à esse modelo tridimensional uma imagem do Google Earth. O cruzamento desses planos de informação possibilitou uma visualização mais precisa da realidade geomorfológica da área, como mostra a Figura 6, possibilitando ao gestor a otimização na aplicação de medidas estruturais e sociais no município através do planejamento e gestão mais adequada do território principalmente quanto ao uso e ocupação do solo e suas implicações no meio ambiente, pois permite visualizar o avanço do perímetro urbano em direção à zona de transição entre as duas unidades geoambientais presentes no município, os baixos planaltos costeiros e a planície litorânea, podendo representar uma área de risco à população que se instalar nessa região, que de acordo com as informações obtidas através dos mapas hipsométrico e clinográfico, é uma área mais vulnerável apresentando relevo elevado com encostas íngremes.

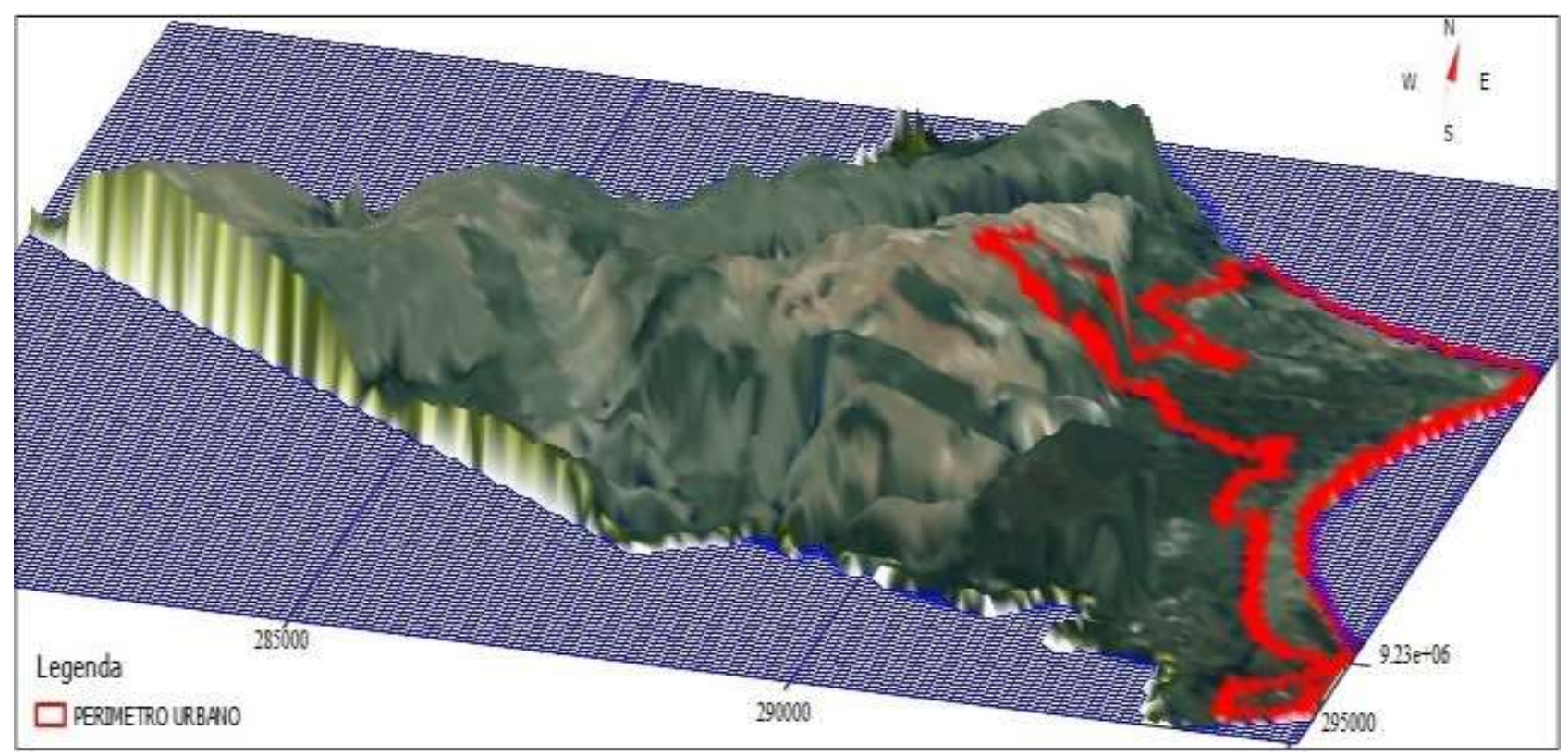

Figura 6. Cruzamento do Modelo tridimensional do SRTM com imagem do Google Earth.

Todos os documentos cartográficos gerados na etapa anterior contribuíram para o processo de compartimentação do relevo de Lucena. Assim, com base nesses mapas e em pesquisas documentais, foi observado que o $1^{\circ}$ táxon corresponde à Formação Barreiras, que ocorre ao longo de todo o litoral brasileiro. $\mathrm{O} 2^{\circ}$ táxon é composto por duas classes morfoescultural, que são: a planície litorânea e os baixos planaltos costeiros (ou tabuleiros).

O $3^{\circ}$ táxon é composto por formas de denudação, que segundo o dicionário livre de geociências, corresponde ao rebaixamento da altitude média de uma área numa certa unidade de tempo, e por formas de acumulação onde são depositados os sedimentos erodidos.

Neste táxon, foram identificadas as formas com topos tabulares e formas de escarpa; e as formas acumulativas de formas de planície interdial (mangue) e formas de campos de dunas.

Os Padrões de Formas de Relevo são acompanhados por um conjunto de algarismos arábicos que indicam o grau de entalhamento dos vales, e a dimensão interfluvial média. Porém, as formas de acumulação não recebem 
os algarismos arábicos, pois não representam dissecação por processos erosivos.

Esse conjunto de algarismos representa o $4^{\circ}$ táxon, dessa forma, foram realizadas as medições das variáveis de entalhamento dos vales e dimensão interfluvial onde os valores obtidos foram classificados segundo a matriz dos índices de dissecação proposta por Ross (1996), representado na Tabela 4. A compartimentação do relevo é representado no Quadro 1.

Quadro 1. Compartimentação do relevo do município de Lucena.

\begin{tabular}{|l|}
\hline $1^{\circ}$ Táxon - Formação Barreiras; \\
\hline $2^{\circ}$ Táxon - Planície litorânea e os Baixos Planaltos Costeiros. \\
\hline $3^{\mathbf{0}}$ Táxon - Formas com topos tabulares; Formas de escarpas; Formas de planície interdial; Formas \\
de campos de dunas. \\
\hline $4^{\circ}$ Táxon -Dissecações do tipo $21,22,23,25,31$ e 32. \\
\hline
\end{tabular}

Os valores obtidos através das medições do grau de entalhamento e da dimensão interfluvial foram comparados à matriz dos índices de dissecação do relevo proposta por Ross (1996), tornando possível concluir que o município de Lucena apresenta dissecações do tipo 21, 22, 23, 25, 31 e 32, com predominância de formas com entalhamento dos vales de intensidade fraca e com dimensão interfluvial média classificada como grande (22) correspondendo a $31 \%$ em áreas de denudação no município; e formas com entalhamento dos vales de intensidade média e com dimensão interfluvial classificada como muito grande (31) correspondendo a $23 \%$ em áreas de denudação no município (Figura 7).

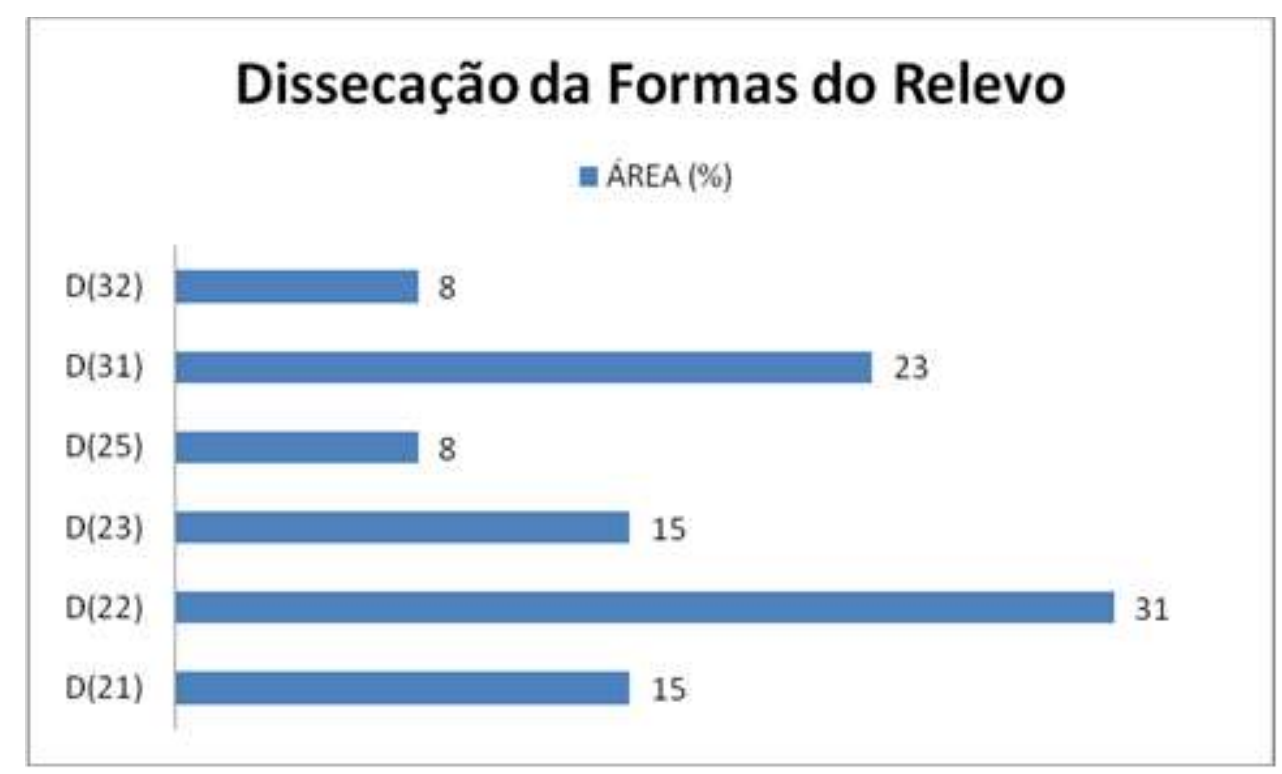

Figura 7. Gráfico dos valores dos tipos de dissecação presentes em Lucena.

Sendo assim, a partir da Figura 11, é possível concluir que no município de Lucena predominam formas de entalhamento fraco com dimensão interfluvial grande (D22) e formas com entalhamento médio com dimensão interfluvial muito grande (D31).
O $5^{\circ}$ táxon refere-se ao estudo das vertentes e foi determinado a partir da análise dos perfis topográficos gerados no SIG SPRING. Para esse estudo foram gerados quatro perfis topográficos no sentido Oeste para Leste (Figura 8). 
(DIAS; SANTOS, 2016)

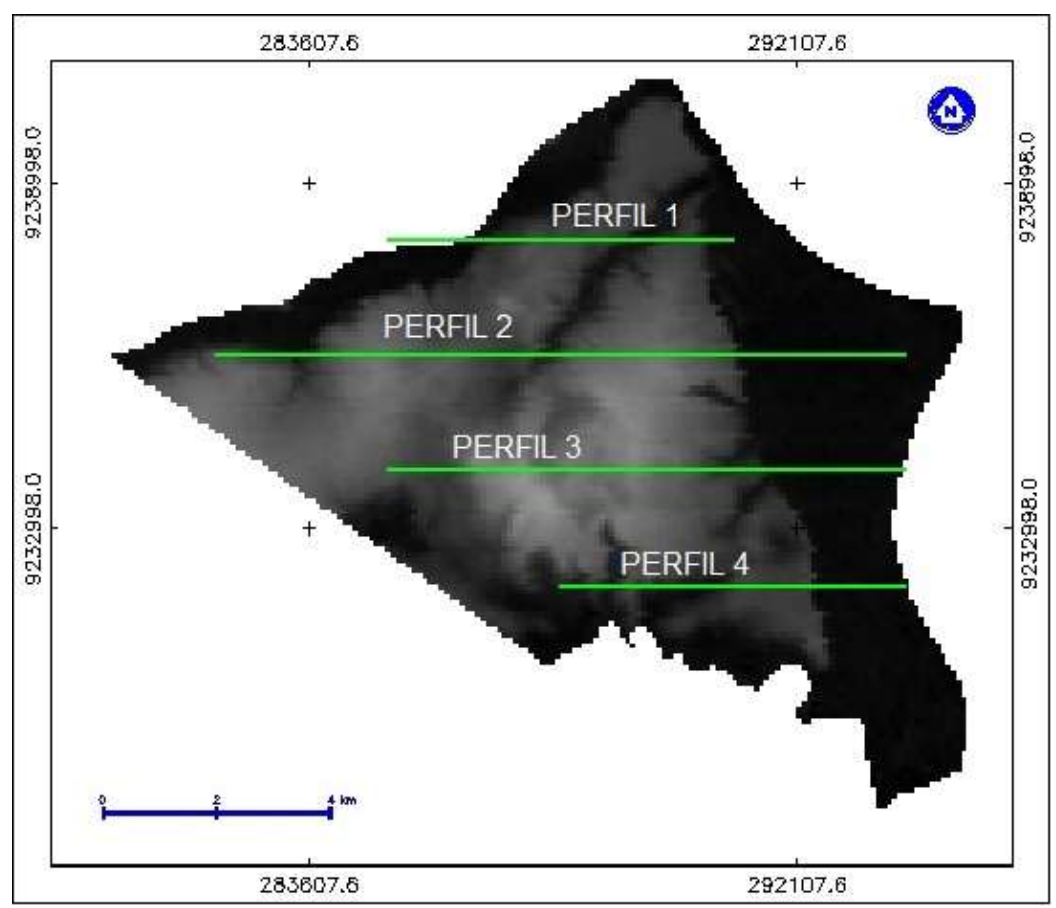

Figura 8. Perfis Topográficos.

Analisando a forma das vertentes côncava na direção Oeste e no ponto mais presentes no Perfil 1 são observadas vertentes do tipo retilíneo-côncava e convexo-retilíneaoriental do perfil, e vertentes convexo-côncavas à Leste, como pode ser verificado na Figura 9.

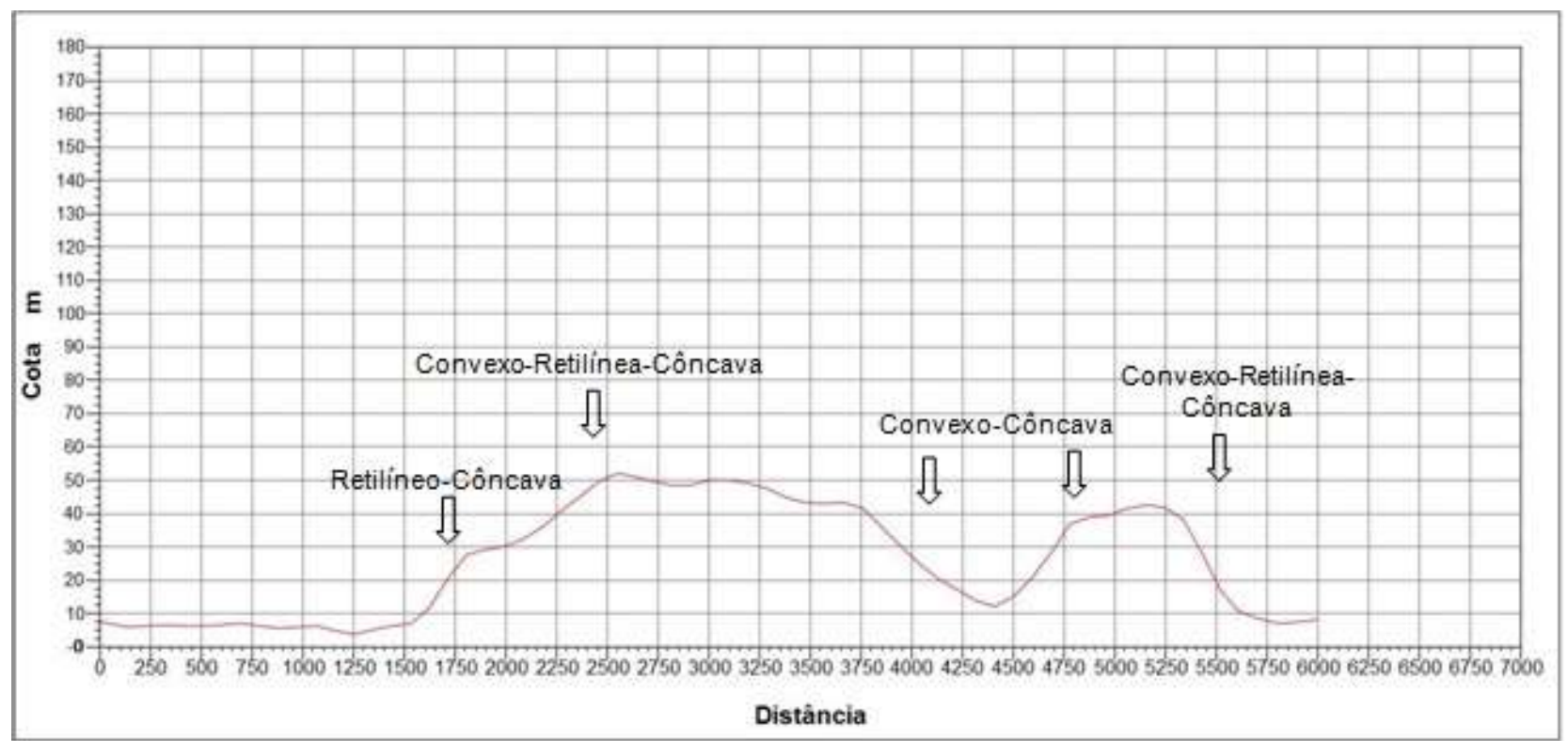

Figura 9. Representação do perfil 1 gerado no SPRING.

Observando a forma das vertentes presentes no Perfil 2 verifica-se a existência de vertentes com forma convexa.
Em outros trechos continua apresentando vertentes com forma retilínea e convexoretilínea (Figura 10). 
(DIAS; SANTOS, 2016)

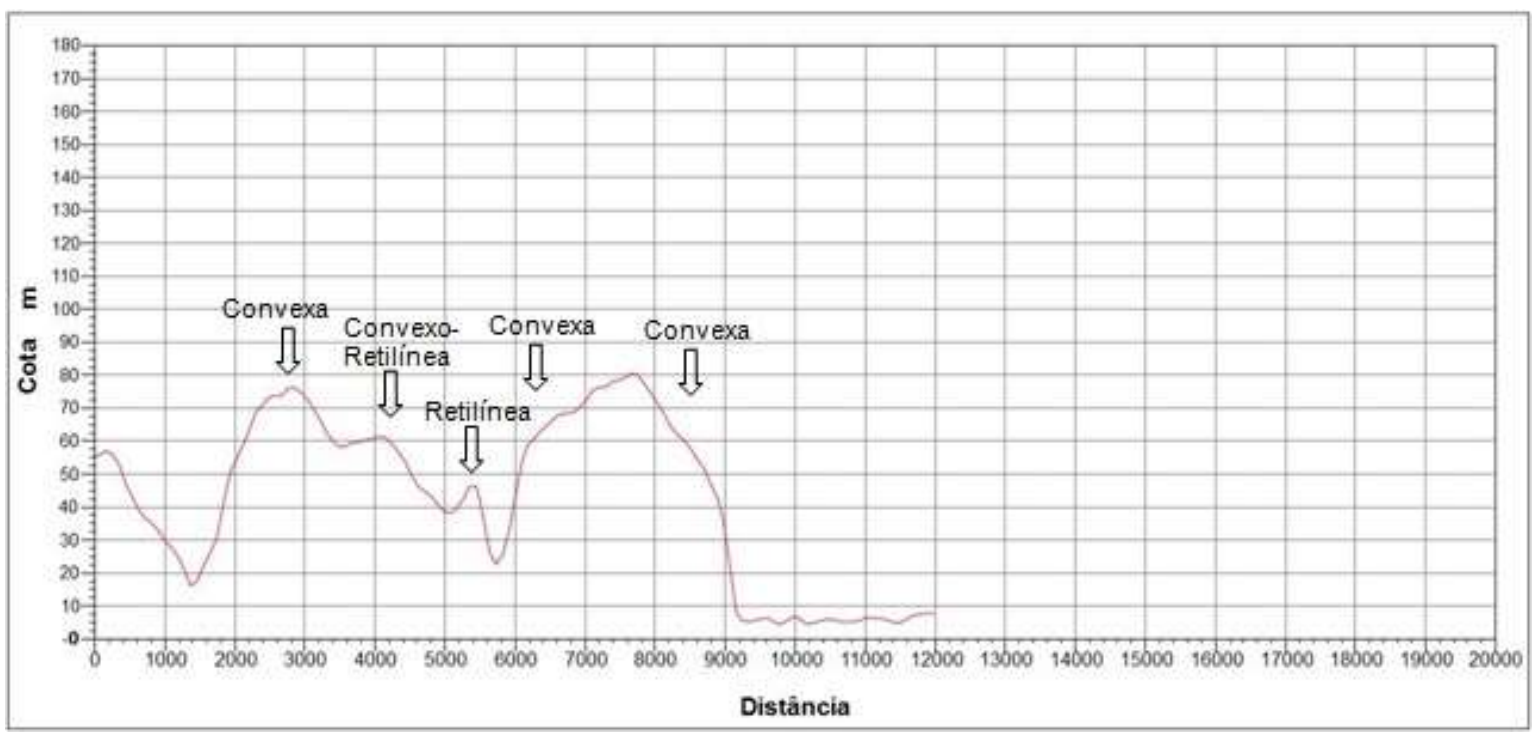

Figura 10. Representação do perfil 2 gerado no SPRING.

As formas das vertentes presentes no Perfil 3 são classificadas do tipo convexo-retilíneacôncava, alternando em alguns trechos com formas do tipo retilínea, retilíneo-côncava e convexoretilínea (Figura 11).

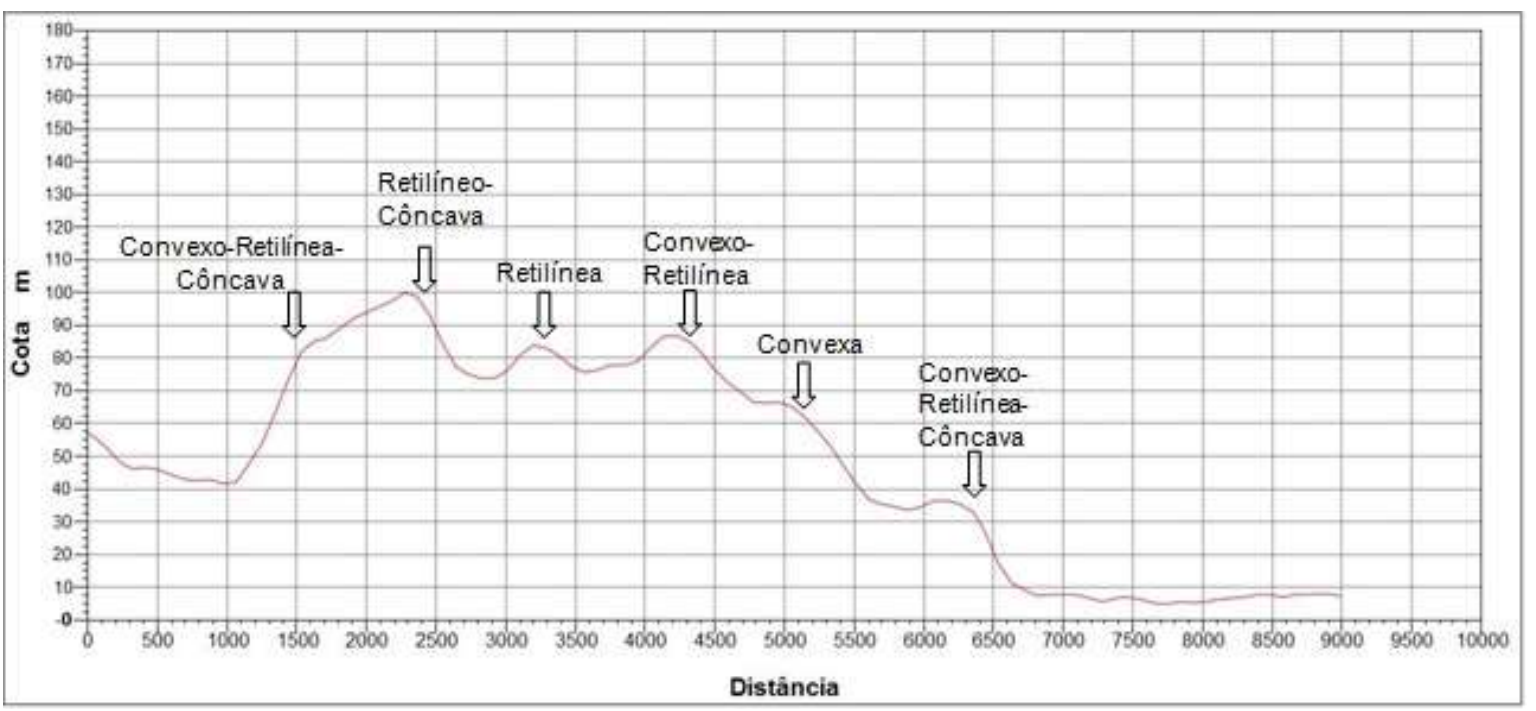

Figura 11. Representação do perfil 3 gerado no SPRING.

O perfil 4 apresenta vertentes com forma do tipo convexa e do tipo retilínea. Além das vertentes, pode-se observar ainda um grande tabuleiro que possui no lado esquerdo vertente do tipo convexo-côncava e do lado direito vertente do tipo retilínea, como mostra a Figura 12. 
(DIAS; SANTOS, 2016)

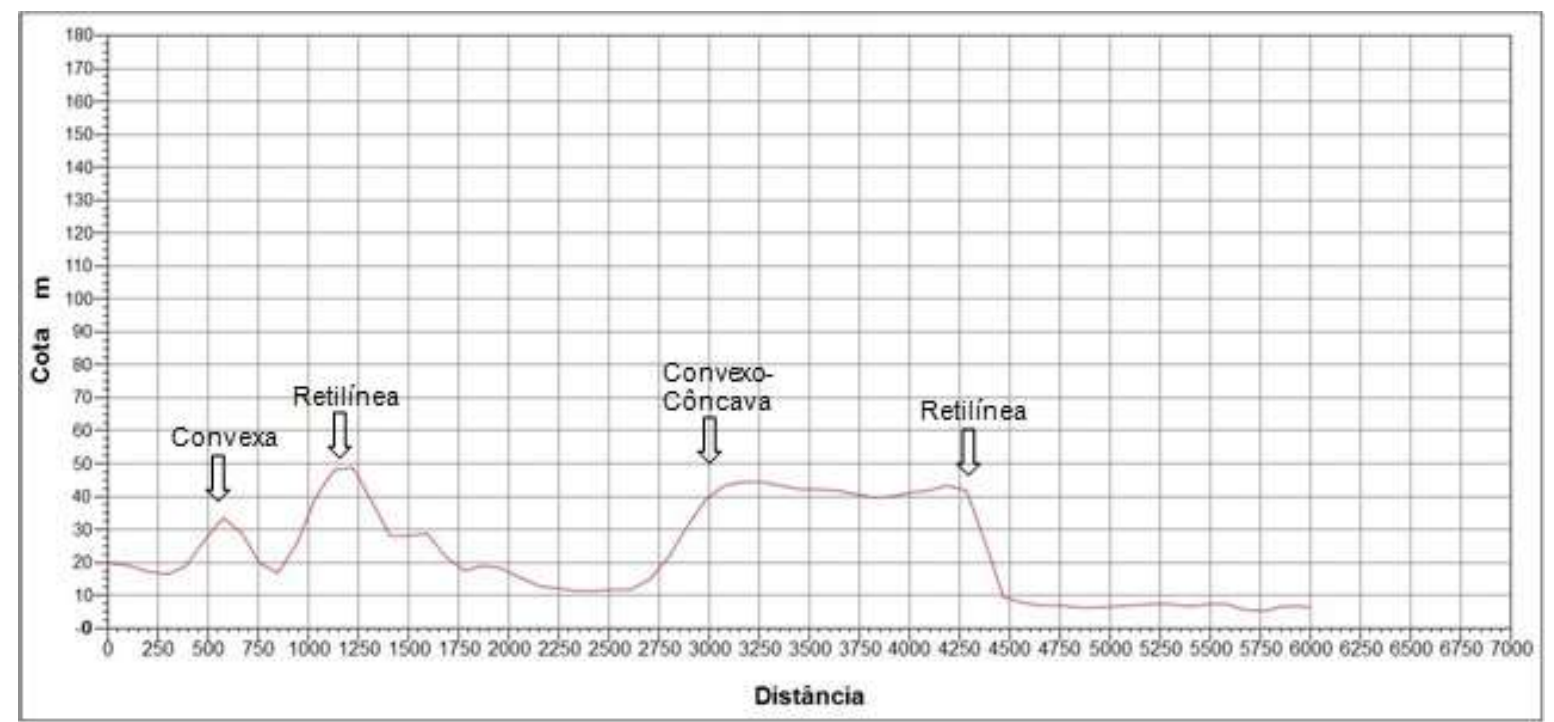

Figura 12. Representação do perfil 4 gerado no SPRING.

Devido ao produto altimétrico utilizado na elaboração desse trabalho ter sido obtido de imagens de radar do SRTM permitindo a geração de mapas na escala 1:100.000, a caracterização geomorfológica foi realizada até o $5^{\circ}$ táxon tomando por base a classificação taxonômica proposta por Ross (1992), pois tal escala não permite o nível de detalhamento necessário para a classificação do $6^{\circ}$ táxon. Após a hierarquização do relevo em unidades morfoestruturais, unidades morfoesculturais, padrões de formas, tipos de formas e tipos de vertentes, foi elaborado o map a geomorfológico do relevo municipal, representado na Figura 13.

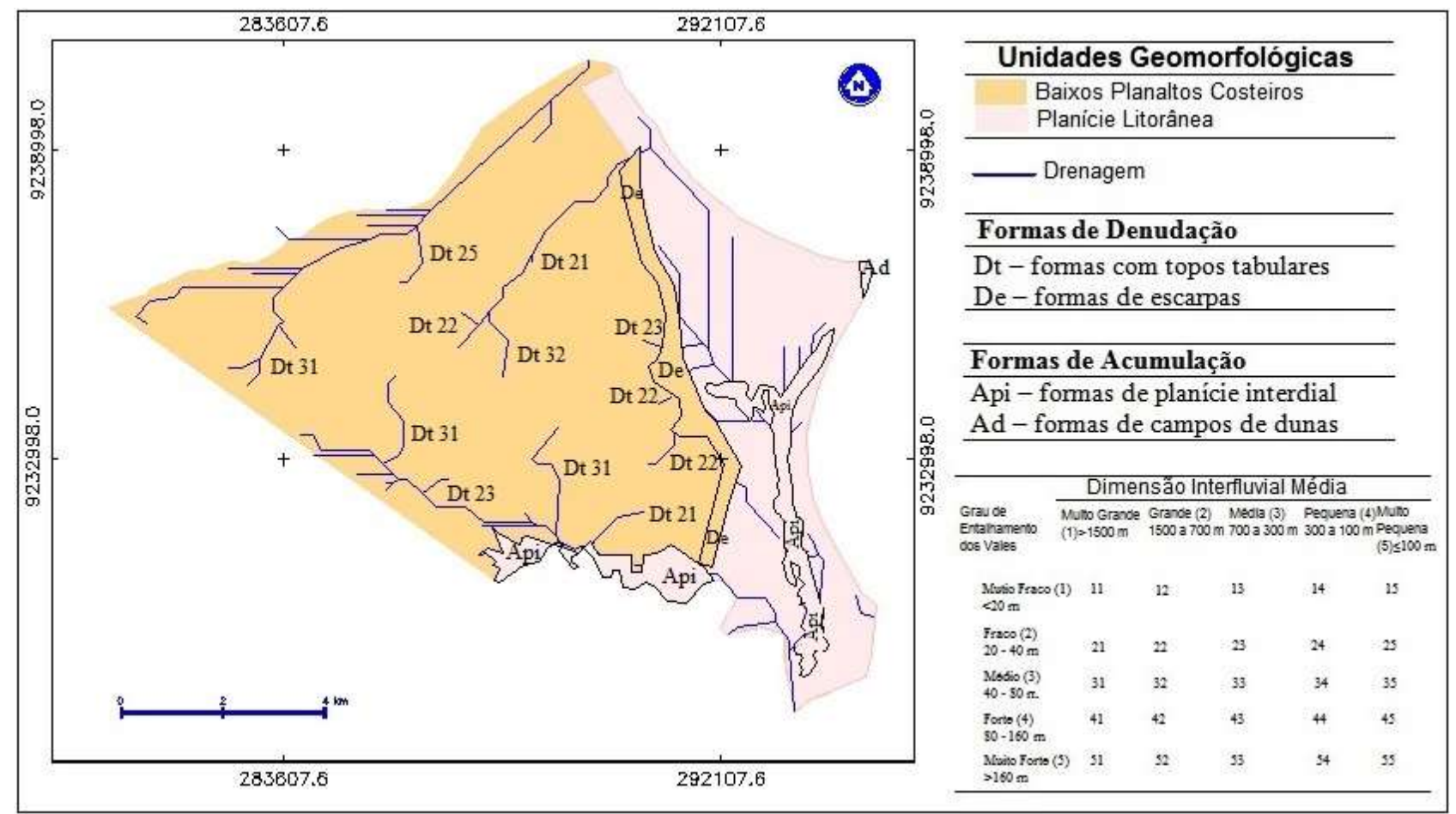

Figura 13. Mapa geomorfológico do município de Lucena.

A partir do mapa geomorfológico e com base nas informações descritas anteriormente, verifica-se que o $1^{\circ}$ táxon é composto pela Formação Barreiras. $\mathrm{O} 2^{\circ}$ táxon por duas classes morfoesculturais: os baixos planaltos costeiros (tabuleiros) e a planície litorânea. $\mathrm{O} 3^{\circ} \mathrm{o} 4^{\circ}$ táxon correspondem aos padrões e aos tipos de forma 
de relevo que foram analisados conjuntamente no qual foi possível observar:

- Áreas de denudação: Compostas por seis tipos de formas: Formas de denudação que apresentam topos tabulares (Dt 21) correspondendo a formas de dissecação que apresentam entalhamento fraco do vale com dimensão interfluvial classificada como muito grande. Formas de denudação tabular do tipo (Dt 22) que apresentam entalhamento fraco do vale com dimensão interfluvial classificada como grande. Formas de denudação com topos tabulares do tipo (Dt 23) apresentando entalhamento fraco do vale com dimensão interfluvial mediana. Formas de denudação tabular do tipo (Dt 25) apresentando entalhamento fraco do vale com dimensão interfluvial muito pequena. Formas de denudação tabular do tipo (Dt 31) apresentando entalhamento médio do vale com dimensão interfluvial muito grande. Formas de denudação tabular do tipo (Dt 32) apresentando entalhamento médio do vale com dimensão interfluvial grande.

- Áreas de acumulação: Compostas basicamente por dois tipos de formas: área de planície de interdial - mangue - (Api), e área de campos de dunas (Ad).

Esse mapa geomorfológico bem como todos os produtos viabilizados através da aplicação das ferramentas de Geoprocessamento, possibilitou o conhecimento do relevo da região de Lucena, como as áreas com terrenos mais íngremes, mais elevados, mais dissecados, podendo assim servir de base para a gestão e planejamento adequado do uso e ocupação do solo e suas implicações no meio ambiente.

\section{Considerações Finais}

O estudo do relevo do município de Lucena, realizado utilizando os dados altimétricos contidos nas imagens SRTM, possibilitou a geração de documentos cartográficos relevantes para o planejamento e gestão territorial do município auxiliando no desenvolvimento de políticas públicas adequadas e eficientes que possibilitem o uso e ocupação do solo de forma racional, fundamental para o município de Lucena que além de possuir poucos estudos dessa natureza, apresenta baixa densidade demográfica, possuindo grande potencial de crescimento planejado.

Contudo, para uma maior precisão e confiabilidade nos dados obtidos e nos produtos gerados, é necessário aliar as informações produzidas neste trabalho à levantamentos topográficos que oferecem maior nível de detalhamento, já que a escala dos mapas produzidos nesse trabalho foi de 1:100.000.

Porém, para alcançar os objetivos propostos e servir de subsídio a estudos futuros bem como à gestão e planejamento físicoterritorial do município de Lucena, auxiliando no desenvolvimento de diagnósticos ambientais que, quando aliada a outras informações como precipitação de chuvas, locais com deposição irregular de resíduos, permitem localizar áreas vulneráveis a alagamentos, enchentes e deslizamentos nas áreas urbanas, as técnicas demonstraram um grande êxito permitindo a geração dos mapas hipsométrico e clinográfico bem como dos modelos tridimensionais que possibilitaram a realização da comp artimentação do relevo no qual foi possível classificar como $1^{\circ}$ táxon a Formação Barreiras; o $2^{\circ}$ táxon como sendo as unidades geoambientais daPlanície litorânea e dos Baixos Planaltos Costeiros; o $3^{\circ}$ táxon como formas com topos tabulares, formas de escarp as, formas de planície interdial e formas de campos de dunas; o $4^{\circ}$ táxon apresentando dissecações do tipo $21,22,23,25,31$ e 32 ; e o $5^{\circ}$ táxon com vertentes mistas. Essa compartimentação possibilitou a geração do mapa geomorfológico do município de Lucena que servirá como subsídio à gestão do território municipal.

Este trabalho também pode servir de base para estudos futuros visando uma análise mais profunda do relevo bem como da rede de drenagem do município de Lucena, utilizando como dados primários, informações planialtimétricas produzidas em escalas que apresentem um maior nível de detalhamento, como por exemplo, as cartas disponíveis no INTERPA (Instituto de Terras e Planejamento Agrícola do Estado da Paraíba) em escala 
1:10.000, possibilitando uma comparação dos produtos gerados nessa escala com os produtos gerados nesta pesquisa.

\section{Agradecimentos}

À prefeitura municipal de Lucena e a todos os órgãos que contribuíram disponibilizando dados que auxiliaram na construção desse trabalho.

\section{Referências}

CAMARA, G. MEDEIROS, J.; Geop rocessamento para Projetos Ambientais In: CAMARA, Gilberto; DAVIS, C. e MONTEIRO, A. M. V. (Org.). Introdução à Ciência da Geoinformação. 1. ed. São José dos Campos, INPE, 2004.

CPRM - Serviço Geológico do Brasil. Projeto cadastro de fontes de abastecimento por água subterrânea, Estado da Paraíba: Diagnóstico do município de Lucena. Organizado [por] João de Castro Mascarenhas, Breno Augusto Beltrão, Luiz Carlos de Souza Junior, Franklin de Morais, Vanildo Almeida Mendes, Jorge Luiz Fortunato de Miranda. Recife: CPRM/PRODEEM, 2005.

FARIA, R.; PEDROSA, A. Aplicação SIG na Elaboração de Cartografia Temática de Base na Bacia Hidrográfica do Rio Uíma -Santa Maria da Feira. In: Anais do XI Simpósio Brasileiro de Geografia Física Aplicada. 2005. Universidade de São Paulo. São Paulo.

FREIRE, F.; PAREDES, E. A. Aplicação do software Global Mapper 8.0 na elaboração de mapas temáticos no planejamento territorial. In: Anais do I Seminário de Engenharia Urbana da Universidade Estadual de Maringá. Maringá. 2007.

GROHMANN, C. H.; RICCOMINI, C.; STEINER, S. S. Aplicações dos modelos de elevação SRTM em geomorfologia. Revista Geográfica Acadêmica, v. 2, p. 73-83, 2008.
PENHA, A. L. T; SILVA, D. C. Correção de Erro de Altitude em MDS Aster-Gdem em Delimitação de Bacia Hidrográfica. In: IV SIMGEO. 2012. Recife. Anais: IV Simnósio Brasileiro de Ciências Geodésicas e Tecnologias da Geoinformação. Recife: Decart/UFPE, 2012. v. 1. p. 1-9.

ROSS, J. L. S. O registro dos fatos geomórficos e a questão da taxonomia do relevo. Revista do departamento de geografia da FFCH/USP. São Paulo, v. 6. p. 17-29, 1992.

ROSS, J. L. S. Análise empírica da fragilidade dos ambientes naturais e antropizados. Revista do Departamento de Geografia, n. 8, p. 1-74, USP, 1994.

ROSS, J. L. S. Geomorfologia aos EIAsRIMAs. In: TEIXEIRA GUERRA, A. J.; CUNHA, S. B. Geomorfologia e meio ambiente. Rio de Janeiro: Bertrand Brasil, 1996. p. 291-336.

USGS - Science For A Changing World. 2008. Disponível em: <http://srtm.usgs.gov/index.php >. Acessado em 01/01/2014. 